\title{
Severe psychiatric disturbance and abnormalities of the corpus callosum: review and case series
}

\author{
Anthony S David, Alisa Wacharasindhu, W Alwyn Lishman
}

\begin{abstract}
The association between developmental defects of the corpus callosum and major psychiatric disturbance is discussed with a review of published cases. Seven new cases are presented, of which four had clear psychotic symptoms, two receiving a diagnosis of schizophrenia. Of the remainder, one had a developmental disorder affecting social interaction and speech which could be classed as Asperger's syndrome, one had a personality disorder with depressive and conversion symptoms, and the last was an adolescent boy with severe behavioural problems. The difficulties in determining the precise relevance of the callosal anomalies to these clinical manifestations are discussed especially since the prevalence of such anomalies in the population is uncertain.
\end{abstract}

(F Neurol Neurosurg Psychiatry 1993;56:85-93)

The corpus callosum (CC) contains the largest nerve fibre tract in the human brain, connecting the cerebral hemispheres with one another. It is estimated to contain nearly 200 million fibres. The CC together with the anterior and hippocampal commissures form the forebrain commissures. The tract develops intimately in association with the fornix, hippocampal commissure, hippocampal formation, septum pellucidum and cingulate cortex, beginning to form shortly after the anterior commissure.

Details of the anatomy and embryology of the CC have been well described. ${ }^{1-4}$ Abnormal morphologies of the CC can be classified into acquired and congenital defects. Acquired changes can result from trauma, tumours, hydrocephalus, vascular accidents and white matter diseases. ${ }^{5}$ Complete agenesis is a rare developmental anomaly of unknown cause and is associated with a wide variety of genetic defects, in particular trisomies of chromosomes, 8, 13 and $18 .^{67}$ Agenesis has also been considered a marker of intrauterine metabolic upsets such as hyperglycinaemia, ${ }^{8}$ and may result from insults such as intrauterine infections and exposure to toxins. ${ }^{39-11}$ The partial forms of agenesis usually affect the posterior portions and are presumed to reflect the action of pathogenic influences occurring after the initial development of the commissures, that is, after the sixteenth week of gestation.

Agenesis is frequently accompanied by other developmental defects. These encompass common midline abnormalities (for example, cleft palate), although other ocular and spinal abnormalities may occur. ${ }^{6}$ The associated brain anomalies which have been reported include interhemispheric cysts with hydrocephalus (Dandy-Walker malformation), lipomas of the CC or interhemispheric fissure, invariably associated with partial agenesis, absence of the inferior cerebellar vermis, and disorders of neuronal migration. ${ }^{12}$ The cingulate gyrus is invariably abnormal and limbic structures may also be affected.

The main function of the CC is interhemispheric integration: connecting corresponding regions of the cerebral cortex in the two hemispheres. Crudely, it serves as a conduit for transfer of sensory information, ${ }^{13-15}$ although the precise nature of the information transferred and its overall influence on the activity of the hemispheres is a topic of continued research and speculation. ${ }^{16}$ It has been noted repeatedly that in agenesis of the CC there is an absence of most aspects of the disconnection symptoms which affect subjects who have had surgical separation of the commissures-the "split-brain operation". 1718 This has been attributed to the presence of alternative pathways connecting the hemispheres such as the anterior commissure, which is frequently intact despite callosal agenesis, or subcortical channels. Other compensatory mechanisms may also play a part such as the duplication of those specialised functions which are usually distributed asymmetrically between the hemispheres, such as speech. Nevertheless, some failures of interhemispheric communication have been noted such as reduced transfer of maze learning from one hand to another, ${ }^{19}$ impaired matching of visual patterns between the right and left visual fields ${ }^{20}$ and reduced transfer of incongruent word stimuli in a colour naming task, ${ }^{21}$ (but see ${ }^{22}$ ).

The prevalence of callosal agenesis is difficult to quantify. Widely varying estimates in the literature, ranging from $0.004 \%$ to $2 \cdot 64 \%$, reflect the different study populations (tables 1 and 2). Thus paediatric neurology services will give higher rates than necropsy studies of unselected members of the population. Similarly, the rates of associated abnormalities and clinical problems reflect the setting in which cases are evaluated. All that can be stated is that certain presentations, namely learning disability and epilepsy are rather common, ${ }^{31730}$ the latter usually estimated at around $40 \%$. Despite most cases coming to light because of the need to investigate a manifest neurological syndrome, many series 
Table 1 Proportion (\%) of individuals with callosal agenesis from necropsy and invasive encephalography

\begin{tabular}{|c|c|c|}
\hline Authors & Proportion (\%) & Setting \\
\hline $\begin{array}{l}\text { Carpenter and } \\
\text { Druckniller (1953) }\end{array}$ & $7 / 3770(0 \cdot 2 \%)$ & Paediatric \\
\hline $\begin{array}{l}\text { Thierffry et al, } \\
(1958)^{24} \\
\text { Gross and Hoff }\end{array}$ & $8 / 1349(0.6 \%)$ & Paediatric \\
\hline$(1959)^{25}$ & $12 / 455(2 \cdot 64 \%)$ & $\begin{array}{l}\text { Severely mentally retarded } \\
\text { institutionalised }\end{array}$ \\
\hline Grogono $(1968)^{26}$ & $\begin{array}{l}50 / 6450(0.7 \%) \\
1 / 19000(0.0053 \%)\end{array}$ & $\begin{array}{l}\text { - Paediatric } \\
\text { - Necropsy series (unselected) }\end{array}$ \\
\hline $\begin{array}{l}\text { Courville }(1950)^{27} \\
\text { cited in } \\
\text { Myrianthopoulos }(1987)^{28}\end{array}$ & $\begin{array}{l}2 / 40000(0.005 \%) \\
1 / 20074(0.005 \%) \\
1 / 24700(0.004 \%) \\
3 / 40100(0.0075 \%)\end{array}$ & $\begin{array}{l}\text { - Necropsy series (unselected) } \\
\text { WHO study } \\
\text { - Czechoslovakia: case had multiple } \\
\text { congenital abnormalities } \\
\text { - Mexico City: stillbirth } \\
\text { NCPP (Collaborative Perinatal } \\
\text { Project) } \\
\text { - } 1 \text { child with multiple abnormalities } \\
\text { and } 2 \text { cases detected during } 7 \text { year } \\
\text { follow up }\end{array}$ \\
\hline
\end{tabular}

Table 2 Proportion of individuals with callosal agenesis from $C T$ and MRI scanning

\begin{tabular}{|c|c|c|}
\hline Authors & Proportion (\%) & Setting \\
\hline $\begin{array}{l}\text { McLeod } \\
(1987)^{5}\end{array}$ & $\begin{array}{l}10 / 450(2 \cdot 22 \%) \\
-2 \text { complete agenesis } \\
-5 \text { partial agenesis } \\
-3 \text { callosal cysts }\end{array}$ & Neurology \\
\hline $\begin{array}{l}\text { Aicardi } e t \text { al } \\
(1987)^{3}\end{array}$ & $3 / 4097(0.073 \%)$ & Paediatric neurology \\
\hline $\begin{array}{l}\text { Swayze et al } \\
\quad(1990)^{29}\end{array}$ & $\begin{array}{l}8 / 7240(0 \cdot 11 \%) \\
-5 \text { agenesis } \\
-3 \text { lipoma }\end{array}$ & Adult neuroradiology \\
\hline
\end{tabular}

include a number of "asymptomatic" cases. Slager et al ${ }^{31}$ collected 23 asymptomatic cases from 170 reviewed in the literature $(13.5 \%)$, and a recent survey from a children's hospital reported $23 / 105(21 \%)$ such individuals. ${ }^{12}$ Nowadays, most cases are identified from CT, MRI brain scans or ultrasonography in pregnancy. Since the "threshold" for carrying out these non-invasive investigations is much lower than invasive studies such as air encephalography (AEG), we would anticipate a increase in the identification of relatively symptom-free cases.

A male preponderance of cases has been claimed especially in developmentally disabled groups ${ }^{6}$ though some large series have failed to confirm this. ${ }^{312}$

Another related problem is case definition. Surveys differ as to whether they accept partia! agenesis as "cases". Again, this issue is liable to result in differences between early and late studies since "focal attenuation" is especially likely to be identified using modern neuroimaging techniques, in particular MRI. McLeod et $a l,{ }^{5}$ report that as many as $112 / 450(24 \cdot 8 \%)$ of their patients who were scanned had significant attenuations, defined as a $50 \%$ or greater thinning of the CC.

This paper considers the association between developmental abnormalities of the $\mathrm{CC}$ and severe psychiatric disturbances.

\section{Methods}

A review of the literature based upon Index Medicus and review articles published since the 1969 edition of the Handbook of Neurology was carried out. Four cases of schizophrenia, one of an atypical psychosis and two in whom significant depression is mentioned, have been reported to date. Four out of the seven were female. The cases are summarised in table 3. In addition, Njiokiktiien, ${ }^{7}$ mentions 4 children in his personal series with behavioural disturbances leading to psychiatric care and mentions one in whom there was a "temporary psychosis". Of the cases in table 3 described in detail, at least 4 could be regarded as having normal or near normal intelligence and none had epilepsy, although Lehmann and Lampe's second case had paroxysmal activity in her

Table 3 Summary of published reports on psychiatric patients with callosal abnormalities

\begin{tabular}{|c|c|c|c|c|c|c|c|c|}
\hline Authors & $\begin{array}{l}\text { Age } \\
\text { (years) }\end{array}$ & Sex & $\begin{array}{l}\text { Age of } \\
\text { onset }\end{array}$ & Clinical features & Diagnosis & $\begin{array}{l}\text { Psycho- } \\
\text { metry }\end{array}$ & $\begin{array}{l}\text { Epilepsy } \\
\text { IEEG }\end{array}$ & $C T / M R I$ scan \\
\hline $\begin{array}{l}\text { Lehmann and } \\
\text { Lampe } \\
(1970)^{19} \text { Case } 1\end{array}$ & 60 & $\mathrm{~F}$ & 47 & $\begin{array}{l}\text { Recurrent } \\
\text { episodes }\end{array}$ & Depression & $\begin{array}{l}\text { VIQ } 88 \\
\text { PIQ } 90\end{array}$ & Normal & \multirow{2}{*}{$\begin{array}{l}\text { complete } \\
\text { agenesis } \\
\text { (AEG) } \\
\text { complete } \\
\text { agenesis } \\
\text { (AEG) }\end{array}$} \\
\hline Case 2 & 50 & $\mathbf{F}$ & 49 & $\begin{array}{l}\text { Insomnia } \\
\text { Suicidal } \\
\text { Family history }\end{array}$ & Depression & $\begin{array}{l}\text { VIQ } 85 \\
\text { PIQ } 83\end{array}$ & $\begin{array}{l}\text { Paroxysmal } \delta \\
\text { both temporal } \\
\text { regions }\end{array}$ & \\
\hline $\begin{array}{l}\text { MacPherson } \\
\text { et al }(1987)^{32}\end{array}$ & 18 & $\mathbf{M}$ & $?$ & $\begin{array}{l}\text { Midline } \\
\text { facial defects } \\
\text { L eye enucleated }\end{array}$ & $\begin{array}{l}\text { Admitted with } \\
\text { psychosis }\end{array}$ & $?$ & $?$ & $\begin{array}{l}\text { Lipoma of CC } \\
\text { Calcification of } \\
\text { falx }\end{array}$ \\
\hline $\begin{array}{l}\text { Lewis et al } \\
(1988)^{33}\end{array}$ & 55 & $\mathbf{M}$ & 30 & $\begin{array}{l}\text { Paranoia } \\
\text { Hallucinations } \\
\text { Violent and suicidal } \\
\text { behaviour } \\
\text { Treatment responsive }\end{array}$ & Schizophrenia & $\begin{array}{l}\text { VIQ } 75 \\
\text { PIQ } 93\end{array}$ & Normal & $\begin{array}{l}\text { Agenesis } \\
\text { L fronto- } \\
\text { temporal cyst }\end{array}$ \\
\hline $\begin{array}{l}\text { Velek et al } \\
(1988)^{34}\end{array}$ & 24 & $\mathrm{~F}$ & 24 & $\begin{array}{l}\text { Persecution } \\
\text { Passivity } \\
\text { Auditory } \\
\text { hallucination } \\
\text { Partial response } \\
\text { to treatment }\end{array}$ & $\begin{array}{l}\text { Schizophrenia } \\
\text { (acute) }\end{array}$ & $\begin{array}{l}\text { VIQ } 103 \\
\text { PIQ } 97\end{array}$ & Normal & $\begin{array}{l}\text { Subtotal } \\
\text { agenesis } \\
\mathrm{R}>\mathrm{L}\end{array}$ \\
\hline $\begin{array}{l}\text { Swayze et al } \\
(1990)^{29} \text { Case } 1\end{array}$ & 39 & $\mathrm{~F}$ & 33 & $\begin{array}{l}\text { Hallucinations } \\
\text { since childhood } \\
\text { Delusions } \\
\text { Refractory to } \\
\text { treatment }\end{array}$ & Schizophrenia & $\begin{array}{l}\text { "border- } \\
\text { line" }\end{array}$ & Normal & $\begin{array}{l}\text { "Nearly } \\
\text { complete } \\
\text { agenesis" }\end{array}$ \\
\hline Case 2 & 33 & $\mathbf{F}$ & 24 & $\begin{array}{l}\text { Persecution } \\
\text { Auditory } \\
\text { hallucination } \\
\text { Refractory to } \\
\text { treatment }\end{array}$ & Schizophrenia & $\begin{array}{l}\text { College } \\
\text { student }\end{array}$ & Normal & $\begin{array}{l}\text { Lipoma } \\
\text { replacing } \\
\text { CC }\end{array}$ \\
\hline
\end{tabular}


EEG. The two cases described by Swayze et $a l^{29}$ were poorly responsive to treatment while the cases of Lewis $e t a^{33}$ and Velek et $a l^{34}$ did respond to some extent. The symptom profiles of these cases do not point to any clear distinguishing characteristics which clinicians could identify.

\section{Case series}

A register of abnormal CT scans from the Maudsley hospital radiology unit was used to trace all psychiatric cases with agenesis or partial agenesis of the CC over a 7 year period (see table 4). Six were referred to a specialist neuropsychiatric unit at the Maudsley hospital. One of these was investigated for possible pseudo-seizures when unsuspected callosal agenesis was revealed. The seventh case was seen in the children's department of the Maudsley hospital. Only one was female.

Case 1 A 35 year old man. Childhood and development were unremarkable. He attended normal schooling and left at the age of 15 with no qualifications but was numerate and literate. He held casual jobs between the age of 15 and 16 but has not worked subsequently. There was no clear family history of psychiatric disorder although his mother had multiple sclerosis and was said to suffer from mood swings.

Psychiatric history started at age 17 when he was diagnosed as having "an adolescent identity crisis", and was treated with outpatient psychotherapy. The first psychiatric admission was at age 19, when the patient was noted to be vague, perplexed, hallucinated and was treated with phenothiazines. There was a further admission in the same year when he was depressed and deluded and possibly thought disordered. Antipsychotic medication and ECT were given with good response. There were 3 further admissions yearly due to similar problems. He was noted early on to have a destructive propensity.

At the age of 25 he had his sixth admission when he was compulsorily detained following an assault on a police officer. Since then he has required almost continuous inpatient care and has received various forms of antipsychotic medication and further courses of ECT. The introduction of carbamazepine showed a marginal effect on his outbursts of aggression. The mental state has fluctuated although thought disorder, persecutory delusions and bizarre hypochondriacal delusions have all been prominent. At the age of 30 he was transferred to a secure unit because of serious aggression towards staff. The mental state examination at this time showed disordered thinking with many shifting persecutory themes, for example, "People make me do things I don't want to ... to kill ... I'm going ... what's this backtracking ... TV and radio". He had ideas of persecution and bizarre somatic delusions such as, "All the bones in my hands are crushed and broken". His attention and concentration were poor. $\mathrm{He}$ is now undergoing continued treatment and rehabilitation but remains symptomatic and a danger to others. A diagnosis of chronic paranoid schizophrenia was made.

Neuropsychological investigations testing with the WAIS-R at age 30 showed a full scale IQ of 72, a fall of 32 IQ points compared with his score at age 21. Tachistoscopic testing showed normal cross-field matching of colours and simple line drawings. Detailed assessment was repeated when his mental state improved but the IQ remained unchanged. He had scored poorly on the similarities sub-test indicating poor ability to form abstract concepts. Memory testing, using the Weschler logical memory test, paired associate learning, ReyOsterrieth and the Benton Visual Retention test were carried out. The results showed overall poor memory especially spatial memory. The performance on the Trail Making Test was also poor while performance on word fluency showed minor impairment. Performance on the Wisconsin Card Sort test was abnormal with a high number of preserverative errors, suggesting frontal lobe impairment.

CT showed a lipoma in the posterior aspect of the corpus callosums (figure 1). An EEG was performed twice at age 30; the first showed no abnormalities while the second showed some minor dysfunction (see table 4).

Case 2 A 29 year old man was born six weeks prematurely, experienced lack of oxygen at birth and was of low birth weight. Motor development was slow: at twelve months he had to be propped up to sit and was noticed by his mother to sit with his legs in a scissored position. The diagnosis of cerebral palsy was made. He could not crawl until aged five, and had surgical operations on leg tendons at the ages of 10 and 12 enabling him to walk with crutches. The patient had episodes of febrile convulsions between the ages of 2 and 4 which were characterised by generalised twitching. $\mathrm{He}$ attended schools for the physically handicapped. Academically he was hampered by "severe spatial problems" and he was poor at maths and woodwork.

Epileptic fits began at age eight. He was treated with a combination of phenytoin and phenobarbitone and achieved relatively good control. During adolescence he began to experience more complex seizures. These began when he saw a vision of the "judgement day" and occasionally, the "whole world's grave opening". This was associated with the thought that he was dying and a sense of losing contact with reality. The fits began with the patient calling out followed by twitching of the left side of the mouth, then eyelids, and finally generalised jerking of all four limbs. He would also shout quotations from the Bible or plead to God to take him. These occurred approximately monthly.

Psychiatric illness began in adolescence. At 13 he was noted to be anxious and having difficulty "distinguishing reality and unreality". At 15, he was admitted to hospital experiencing auditory hallucinations, and preoccupied with religious and sexual ideas. He was treated with a combination of antidepressants and neuroleptics. When assessed at age 
25 he believed that he had been chosen by God and described the experience of God speaking to him.

Physical examination showed a divergent squint and a defect in his iris. There was facial asymmetry and he had marked spastic diplegia with tendon reflexes increased bilaterally. Mental state examination at age 29 revealed an anxious and irritable man, occasionally overfamiliar. He showed some thought disorder and was incoherent at times with circumstantial and tangential speech. There was marked interpenetration of themes reflecting a preoccupation with religious and grandiose delusions. He reported no auditory and visual hallucination apart from those at the time of seizures.

Cognitive testing showed good orientation but some difficulty with concentration. He was unable to do serial $7 \mathrm{~s}$ but could perform both serial $3 \mathrm{~s}$ and naming the months of the year backward slowly and accurately. Digit span was 5 forwards and 4 backwards. He could name 16T-words and 3 four-legged animals on a test of verbal fluency. His writing was poorly formed and done with great difficulty. He was unable to write a sentence of his own creation. His verbal memory was unimpaired but there was some impairment of visual memory with evidence of constructional apraxia. There was some evidence of concrete thinking on word association and proverbs. Comprehension was normal. There was no nominal aphasia, right-

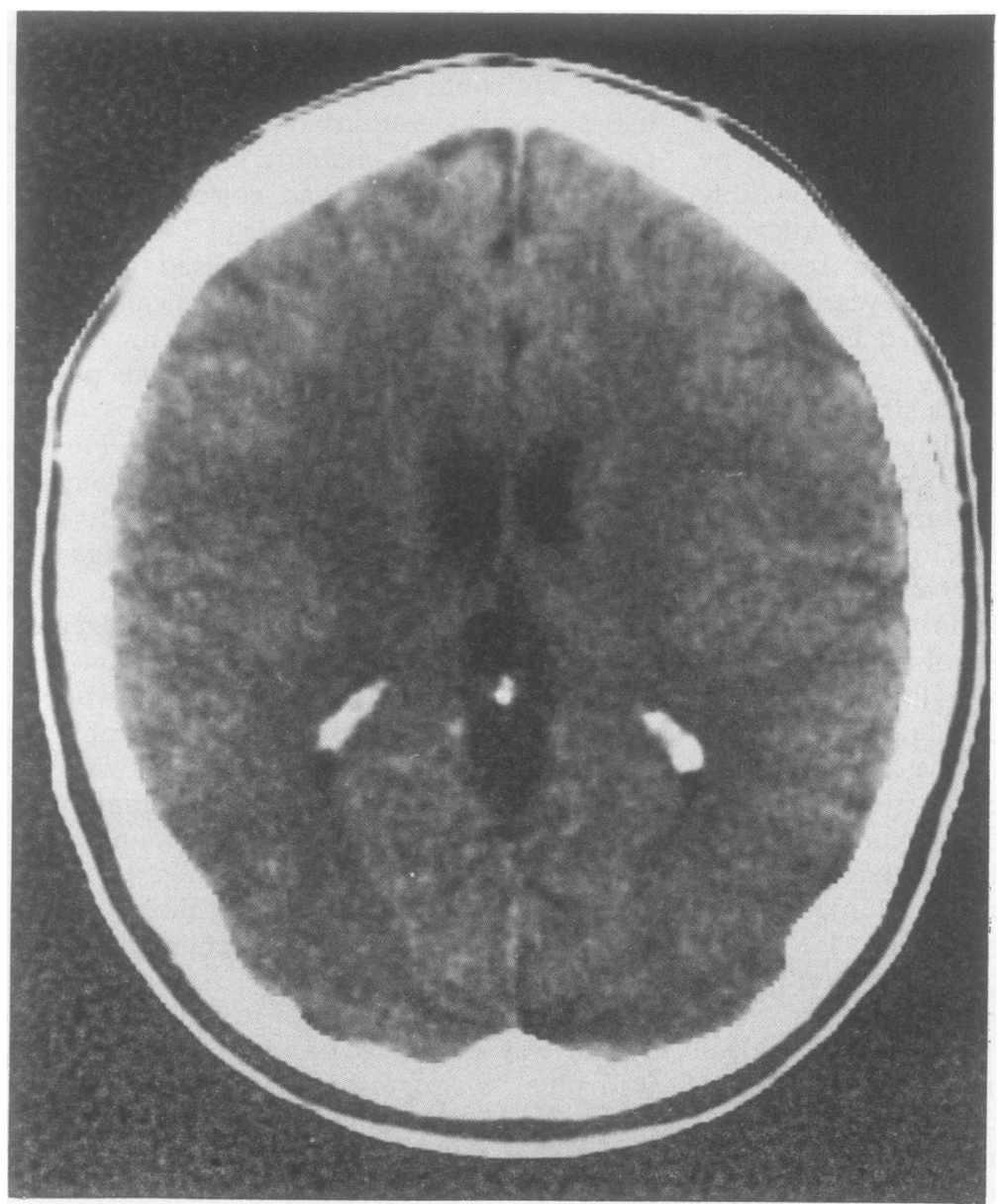

Figure 1 Case 1 CT axial brain scan showing lipoma immediately to the right of the midline within the posterior aspect of the corpus callosum. left disorientation or finger agnosia.

The diagnoses were: cerebral palsy, complex partial seizures with secondary generalisation and chronic schizophrenia.

CT scan at age 25 showed agenesis of the corpus callosum and left hemiatrophy affecting principally the anterior hemisphere where there was a CSF-containing cyst within the left frontal lobe. Adjacent to this there was some atrophy of the sulci extending into the insular region. In addition there was relative dilatation of the posterior horns and bodies of the ventricles adjacent to the upward extension of the widened third ventricle. The EEG was diffusely abnormal with sharp waves over both temporal regions particularly on the right.

Case 3 A 41 year old man. He was a twin, born 3 weeks premature after a forceps delivery and needed oxygen for one week. The birth was also complicated by Rhesus incompatibility. His co-twin died at one week. Macrocephaly was noted during early childhood. His parents reported that he had temper tantrums and breath holding attacks, but no convulsions. $\mathrm{He}$ was said to be a happy child with friends in the local village. He left school at age 17 with 5 CSEs and then worked as a clerk for 6 months. He began basic training for the armed forces but failed and left after 2 months. Since then he has had several unskilled jobs, each lasting short periods, followed by long periods of unemployment due to psychiatric illness. There is no family history of psychiatric illness or epilepsy.

From age 18 he has experienced brief, bifrontal headaches of moderate severity. In addition he has had a total of 6 seizures. These are stereotyped, starting with an abrupt loss of consciousness, followed by tonic-clonic movements.

Psychiatric history started at age 24 with alternating periods of "up" and "down" mood swings. "Up" swings manifest as restless, overactive, irritable and noisy behaviour with pressure of speech. "Down" swings manifest as feeling tired, listless, low in mood, tearful, anhedonic and retarded. He has had numerous hospital admissions due to mood disorder and epilepsy and has been treated with a variety of anticonvulsants, antidepressants, mood stabilisers, antipsychotics, and ECT.

Mental state examination at age 39 revealed tearfulness, low mood and early morning wakening. Speech was odd, pedantic, circumlocutory and metaphorical, but there was no clear evidence of thought disorder and he showed neither delusions nor hallucinations. Cognitive testing was reported to show no abnormalities. At that time his epilepsy was well controlled.

The diagnoses were, manic depressive psychosis, epilepsy and tension headaches. Also, in view of some obsessional features, social avoidance, and his use of language, the possibility of the diagnosis of Asperger's syndrome (or "schizoid personality") was suggested but felt to be inconsistent with his sociability as a child.

Psychometric testing at age 39 revealed a WAIS-R full scale IQ of 86 . Verbal score was 
the same as previous testing at age 26 but performance showed a significant fall of 20 points. Sub-test scores showed that he performed well on tasks involving rote learning and poorly on tasks involving abstract reasoning.

CT and MRI scans showed agenesis of the anterior part of the corpus callosum (fig 2). He had a series of EEGs which showed bursts of generalised rhythmic delta activity and some evidence of left anterior quadrant dysfunction.

Case 4 A 33 year old man. Birth was normal but he showed slow development, only learning to walk at the age of 3 . There were also some behavioural disturbances. At age 5 he set fire to an armchair and at other times he attacked neighbours. He was described as "slow" at school and was advised to have special education. He had no friends and was constantly bullied and "in trouble". He left at age 15 with no qualifications, and had several different menial jobs; the longest period of employment was three and a half years. All his jobs terminated in him being sacked, mostly due to incompetence. $\mathrm{He}$ was involved in several heterosexual and homosexual relation-

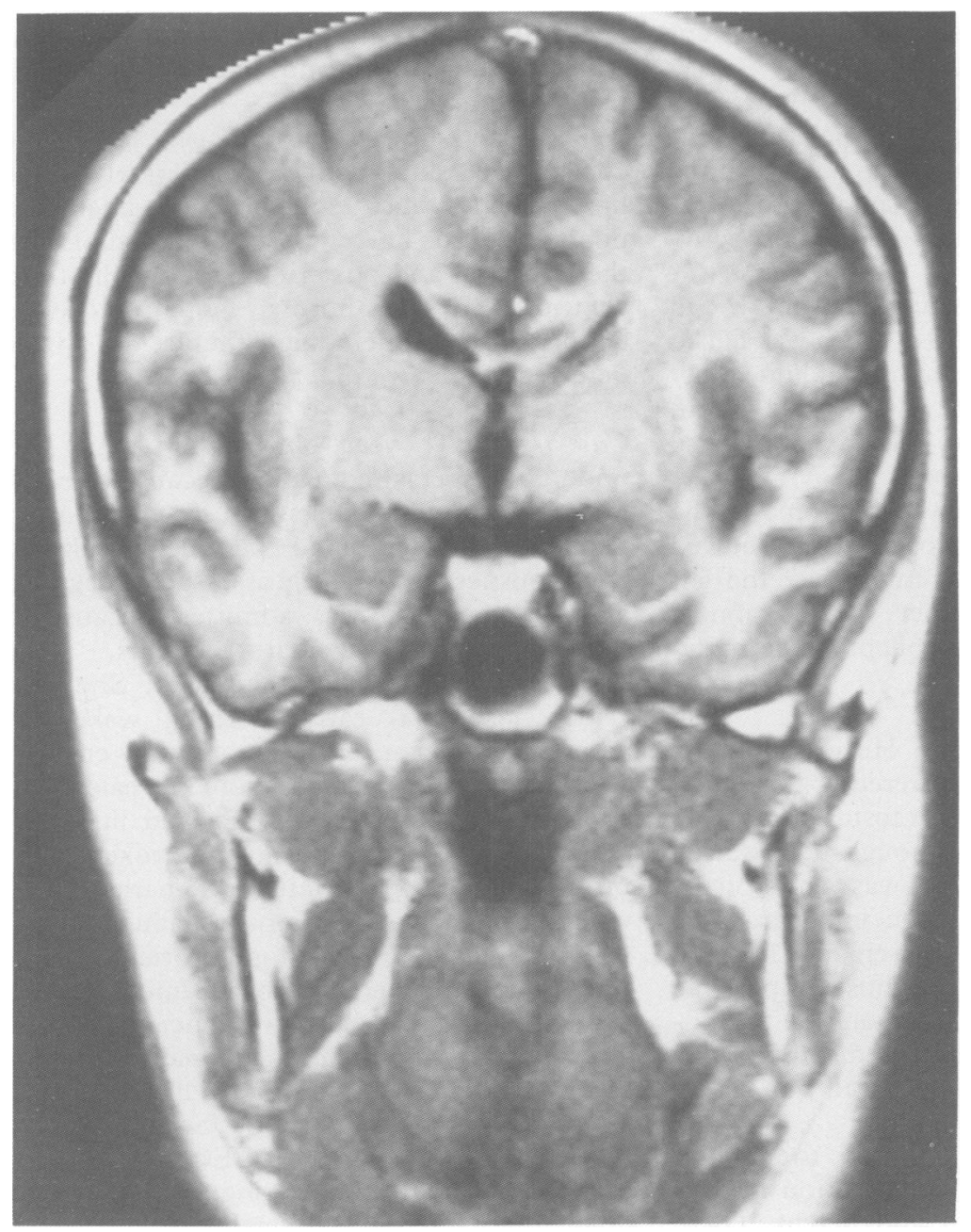

Figure 2 Case 3 Coronal MRI scan showing dysgenesis of the anterior part of the corpus callosum and deformity of the frontal horns. ships. There is no history of drug or alcohol abuse. The only family history of psychiatric disorder is alcohol dependence in the patient's mother.

Psychiatric history started at age 24 following the end of a long homosexual relationship. He started attending a monastery and on one occasion while he was praying he heard "the voice of god" talking close to him saying "Heaven". He felt from that point that he had been chosen as a disciple of Christ. $\mathrm{He}$ also described waking one morning with a terrifying sensation of strangulation and the feeling of an evil presence. He had a strange feeling that he was "meant to commit suicide". He rushed out of bed, looked in the mirror and saw a face which seemed not to belong to him. He described hearing loud noises which he felt represented good and evil coming into conflict. $\mathrm{He}$ also described second person auditory hallucinations and symptoms of acute depersonalisation.

Mental state examination during his admission revealed some mannerisms: repeated raising his eyebrows, flapping his hands around. He showed a combination of fear and anxiety but occasionally seemed to be unconcerned and confused. Grandiose religious delusions were elicited as well as hallucinations of "voices", and visual hallucinations of seeing bright lights flashing in the sky and hallucinations of the smell of oranges. Cognitive testing showed good orientation in time and place but poor concentration tested by digit span and serial $7 \mathrm{~s}$. He showed good immediate memory but poor recent memory when tested by using name and address. Within a week of admission his symptoms had improved completely with no medication except occasional anxiolytics.

The diagnosis was of an acute anxiety state although schizophreniform psychosis must be considered. He was felt to have a dependent personality, with difficulty in relating to other people. Follow up over 2 years showed only discrete episodes of acute anxiety occurring once every 3 to 4 weeks, lasting an hour or so. These were precipitated by interpersonal stresses or vivid images in magazines or on television, and responded to behaviour therapy.

Psychometric test gave a full scale IQ of 78 . The score of Mill Hill was 82 and Progressive matrices was 92. Neuropsychological tests showed some incoordination involving fine motor control and opposing hand movements. Somato-sensory evoked potentials showed no significant abnormality or delay between right and left impulses.

CT scan showed partial agenesis of the anterior part of the corpus callosum. EEG which was done twice, showed no significant abnormality (table 4).

Case 5 A 22 year old man. Birth was normal but he was noted to be slow to develop in comparison with his sister. At school at the age of five years he was reported by the teacher to be an odd and lonely boy, who was teased frequently. He finished schooling with 2 CSEs. During work training he showed poor initiative and failed because of poor concentration, 
turning up in the wrong places and inability to communicate. He was described as a loner who had poor social skills, drive and motivation. He was in good physical health.

Family history revealed that his father had been a quiet and self-contained man but "rather aloof'. Maternal grandfather had a phobic disorder.

At the age of 6 he was referred to a Child Guidance Clinic. He showed anxiety about school, self-absorption, wandering, an "odd" manner, "in a daydream most of the time". He was solitary and enjoyed being on his own with imaginary friends. At the age of 10 he developed obsessional and manneristic symptoms. His talk was difficult to follow and he had paranoid ideas about school as well as hypochondriacal preoccupations. The diagnosis of schizoid personality was made and he was treated with social skills training.

At age 18 he was referred for psychiatric treatment and has attended a day hospital since then. He was noted to be withdrawn, mumbling, smiling to himself, picking up litter, bumping into walls, trees and fences, and wandering.

Mental state examination showed some oddities of manner and social interaction. Talk was hesitant and hard to understand at times because of disjointedness and mumbling. Written productions were similarly disordered. There was no evidence of abnormal mood, delusions or hallucinations. He was competent in all aspects of self-care.

The diagnosis was uncertain. Asperger's syndrome or simple schizophrenia were considered. $\mathrm{He}$ was treated with antipsychotic medication, attended day hospital with occupational therapy, individual and group activities.

Neuropsychological testing showed a full scale IQ of 85 by the WAIS-R. This was felt to be lower than expected from his reading ability and educational history. Memory for both verbal and visual-spatial material was also found to be poorer than expected.

CT scan at age 18 showed a lipoma in the splenium of the corpus callosum. EEG showed an excess of slow activity, more over the left side but there were neither specific abnormalities nor evidence of epileptogenic activity.

Case 6 A 12 year old boy. He was born by normal delivery. He was fostered at the age of two and had several different foster homes. He attended school regularly though he required extra tuition. His mother was emotionally disturbed when he was taken into care. She had been an inpatient in a psychiatric hospital for a few years and had a diagnosis of possible Huntington's disease. The maternal grandmother died from a similar disorder. The patient had two sibs who were well but also in care.

At age eight he was referred to a child psychiatrist. On physical examination he was just below average weight and height. There was macrocephaly (head circumference $58.5 \mathrm{cms}$ above the 99 th centile). Vision in his right eye was poor - 6/24 (left, 6/6). There was a short metacarpal, a long thin upper lip and long philtrum. Tone on his left side was mildly increased in a cogwheel pattern resulting in poor coordination. Power and sensation were normal, and reflexes normal and symmetrical.

Mental state examination revealed a cooperative boy with normal speech. He was sociable and smiled occasionally. Short and long term memory appeared normal but writing and copying skills were poor. He played imaginatively.

He has had severe behavioural problems. At times he appeared vacant and was destructive at home. His conduct had become progressively more disruptive to family life. He would not join in family activities such as games and meals and set himself apart from the others. In addition he destroyed his belongings including favourite toys. Feeding had been messy, and he had the habit of eating anything he could get hold of, such as soil, rubbish, and grass. He soiled and wet himself deliberately on occasion.

Diagnosis was of a non-progressive congenital neurological lesion. His behaviour problems were treated by standard behavioural techniques for 8 weeks during which time there was some improvement.

Psychological testing revealed a full scale IQ of 88 (WISC-R). He scored below his age level on the Oseretsky motor test ${ }^{35}$ and had difficulty with fine motor movements and bimanual co-ordination.

CT scan showed partial agenesis of the corpus callosum with a moderately large lipoma. The caudate nuclei were small and poorly defined. There was also dilation of both the temporal and posterior horns of the third ventricle. EEG was normal. No chromosomal abnormalities (including fragile $\mathrm{X}$ ) were detected.

Case 7 A 31 year old woman. She had undergone special education because of reading problems. Since the age of 12 she reported "epileptic attacks" and periods of altered consciousness. Psychiatric assessment began at age 29 when she was admitted because of depression and suicidal thoughts, some months after her fiancé had died. She described insomnia, early morning wakening, anorexia, poor concentration and low energy.

Mental state examination revealed an expressionless woman who showed little evidence of depression, but at times joked inappropriately and made fatuous remarks. There was no evidence of delusions or hallucinations. Cognitive testing revealed good orientation in time, place and person, normal memory and general knowledge, but poor concentration.

The diagnosis was of a personality disorder in that she had a long history of histrionic and attention seeking behaviour. "Seizures" were observed in the absence of EEG abnormality. She had no medication during admission, and finally discharged herself against advice.

The patient had neuropsychological testing at age 28 (see table 4). She was mildly 
Table 4 Clinical details of psychiatric patients with callosal abnormalities

\begin{tabular}{|c|c|c|c|c|c|c|c|c|}
\hline Case & $\begin{array}{l}\text { Age } \\
\text { (years) }\end{array}$ & Sex & $\begin{array}{l}\text { Perinatal } \\
\text { /development }\end{array}$ & Clinical features & Diagnosis & Psychometry & Epilepsy/EEG & $C T$ scan \\
\hline 1 & 35 & $\mathbf{F}$ & Long labour & $\begin{array}{l}\text { Persecutory and } \\
\text { bizarre delusions } \\
\text { Hallucinations } \\
\text { Violent behaviour }\end{array}$ & Schizophrenia & $\begin{array}{l}\text { VIQ } 74 \\
\text { PIQ } 73\end{array}$ & $\begin{array}{l}\text { No seizures. } \\
\text { Excess } \Theta, \downarrow a \\
\text { right temporo } \\
\text { occipital }\end{array}$ & $\begin{array}{l}\text { Lipoma of } \\
\text { splenium }\end{array}$ \\
\hline 2 & 29 & $\mathbf{M}$ & Premature & $\begin{array}{l}\text { Early onset } \\
\text { Hallucinations } \\
\text { and delusions }\end{array}$ & $\begin{array}{l}\text { Schizophrenia } \\
\text { Cerebral palsy }\end{array}$ & $\begin{array}{l}\text { "Mild } \\
\text { mental } \\
\text { handicap" }\end{array}$ & $\begin{array}{l}\text { Complex partial } \\
\text { seizures. } \\
\text { Diffuse } \\
\text { abnormality }\end{array}$ & $\begin{array}{l}\text { Agenesis. } \\
\text { L anterior } \\
\text { hemiatrophy } \\
\text { L frontal }\end{array}$ \\
\hline 3 & 41 & $\mathbf{M}$ & $\begin{array}{l}\text { Premature } \\
\text { Macrocephaly }\end{array}$ & $\begin{array}{l}\text { Cognitive deficits } \\
\text { Mood swings } \\
\text { Odd speech } \\
\text { Tension headaches } \\
\text { Fits as teenager }\end{array}$ & $\begin{array}{l}\text { Manic depressive } \\
\text { psychosis }\end{array}$ & $\begin{array}{l}\text { VIQ } 91 \\
\text { PIQ } 81\end{array}$ & $\begin{array}{l}\text { Generalised } \\
\text { epilepsy. } \\
\text { ? Lanterior } \\
\text { dysfunction }\end{array}$ & $\begin{array}{l}\text { cyst } \\
\text { Partial } \\
\text { agenesis } \\
\text { (anterior) }\end{array}$ \\
\hline 4 & 33 & $\mathbf{M}$ & $\begin{array}{l}\text { "Slow" at } \\
\text { school }\end{array}$ & $\begin{array}{l}\text { Early onset } \\
\text { Prominent anxiety } \\
\text { Psychotic } \\
\text { symptoms }\end{array}$ & $\begin{array}{l}\text { ?Anxiety state } \\
\text { ?Schizophreniform } \\
\text { psychosis }\end{array}$ & $\begin{array}{l}\text { VIQ } 86 \\
\text { PIQ } 71\end{array}$ & Normal & $\begin{array}{l}\text { Partial } \\
\text { agenesis } \\
\text { (anterior) }\end{array}$ \\
\hline 5 & 22 & $M$ & $\begin{array}{l}\text { "Slow } \\
\text { developer" } \\
\text { Poor social } \\
\text { relationships }\end{array}$ & $\begin{array}{l}\text { Anxiety age } 6 \\
\text { Mannerisms } \\
\text { Paranoid ideas }\end{array}$ & $\begin{array}{l}\text { Asperger's } \\
\text { syndrome } \\
\text { ?schizophrenia }\end{array}$ & $\begin{array}{l}\text { VIQ } 91 \\
\text { PIQ } 79\end{array}$ & $\begin{array}{l}\text { Excess slow } \\
\text { activity } \\
L>R\end{array}$ & $\begin{array}{l}\text { Lipoma of } \\
\text { splenium }\end{array}$ \\
\hline 6 & 12 & $\mathbf{M}$ & $\begin{array}{l}\text { Minor } \\
\text { physical } \\
\text { anomalies } \\
\text { Macrocephaly }\end{array}$ & $\begin{array}{l}\text { Behavioural } \\
\text { problems, pica } \\
\text { soiling. Family } \\
\text { history of HD. * }\end{array}$ & $\begin{array}{l}\text { ?Juvenile } \\
\text { Huntington's } \\
\text { Disease } \\
\text { Conduct disorder }\end{array}$ & $\begin{array}{l}\text { WISC- } \\
\text { VIQ } 81 \\
\text { PIQ } 99\end{array}$ & Normal & $\begin{array}{l}\text { Partial } \\
\text { agenesis with } \\
\text { large lipoma }\end{array}$ \\
\hline 7 & 31 & $\mathrm{~F}$ & $\begin{array}{l}\text { Reading } \\
\text { impairment }\end{array}$ & $\begin{array}{l}\text { Pseudo-seizures } \\
\text { Depression } \\
\text { Parasuicide }\end{array}$ & $\begin{array}{l}\text { Personality disorder } \\
\text { Conversion } \\
\text { symptoms }\end{array}$ & $\begin{array}{l}\text { VIQ } 87 \\
\text { PIQ } 106\end{array}$ & $\begin{array}{l}\text { "Within normal } \\
\text { limits" }\end{array}$ & Agenesis \\
\hline
\end{tabular}

impaired on tests of verbal memory, immediate spatial recall and memory spans; new learning of verbal and non-verbal materials and longterm spatial memory were intact. She was also impaired in reading with a pattern consistent with surface dyslexia (L Goldstein, personal communication).

CT scan showed agenesis of the corpus callosum. The lateral ventricles were widely separated by the continuous upward expansion of the third ventricle between them. EEG was within normal limits.

\section{Discussion}

Schizophrenia was the most frequent syndrome reported in the new cases and those reviewed. However, we cannot make any definitive statements about the relative risk of schizophrenia in callosal agenesis. Firstly, estimates of the prevalence of the condition in the general population differ widely (tables 1 and 2). Secondly, the reported cases do not come from a defined population so it is impossible to know the "denominator". Even Swayze et al, ${ }^{29}$ who attempted to give some idea of the number of callosal abnormalities seen at the same hospital, were not surveying a defined population and did not take into account the selection factors for MRI scanning in general. One important criterion which will exert a major influence on the rates of callosal abnormalities reported is the exclusion from scanning of patients with IQ less than $80 .^{29}$

The 7 new cases were all tertiary referrals to a specialist neuropsychiatric unit and so our experience cannot be considered representative. Again, no meaningful calculation of rates can be made only to mention that agenesis is a rare accompaniment of psychosis. However, when criteria for normal intellectual functioning are relaxed, more cases are to be anticipated. Two of our cases had mild mental impairment (IQ < 80) and three had "border- line" scores (IQ between 80 and 90)although evidence for deterioration in IQ, presumably as a consequence of psychosis, was present in cases 1 and 3. Similarly, cohorts in which psychosis and epilepsy coexist, may include more cases with abnormal callosa. The same applies to cerebral palsy and patients with other obvious neurological disorders.

The cases in table 4 show that the psychiatric syndromes associated with callosal abnormalities are heterogeneous. Case 4 had a highly atypical disorder characterised by extensive anxiety and psychotic symptoms. Another (case 3), had a classical bipolar affective illness with some features of disordered social interaction and idiosyncratic use of language. The patient described by Lewis et al, ${ }^{33}$ although diagnosed as suffering from chronic schizophrenia, also had experienced marked affective symptoms. Unlike case 3 , however, he had a positive family history of manic depression. Case 5 had a more striking, pervasive disorder of social development than case 3 . This would fit into the rubric of Asperger's syndrome ${ }^{36}$ or schizoid personality disorder. ${ }^{37}$ This syndrome has been described in association with right hemisphere deficits ${ }^{38}$ but neurological anomalies involving the CC could also have a potential aetiological role. Both these cases had significant reductions in performance vs verbal IQ, which, while not unique in our series (see case 4), are somewhat unusual for "uncomplicated" agenesis. ${ }^{17}$ This may relate to functional impairment of the right hemisphere.

The finding of agenesis in case 7 who was finally diagnosed as having a personality disorder with depressive and conversion symptoms, may have been a coincidence. However, it is conceivable that the patient's specific learning disability, possibly a direct consequence of callosal agenesis could have contributed to her poor self-esteem through academic failure $^{35}$ setting off a chain of negative experiences. Other cases in whom early devel- 
opmental problems were noted, may also have suffered from distorted social and family relationships as a result. This may have influenced the onset, course, and form of the eventual psychiatric syndrome, interacting with the "endogenous" brain abnormality. It is not possible to state with any confidence the potential influence of $\mathrm{CC}$ abnormalities on non-psychotic psychiatric disorders since patients so diagnosed rarely undergo comprehensive neurological evaluation.

Are abnormalities of the CC relevant in the understanding of severe psychiatric disturbances? Such disturbances, particularly schizophrenia, have been shown to be associated with a number of disparate abnormalities of brain structure. ${ }^{39-41}$ Deviant brain development, pre-dating the onset of gross disorder is attracting the attention of those who favour a "neurodevelopmental" theory of the origin of schizophrenia. ${ }^{42}$ Cases such as those reported here, with abnormal premorbid personalities, atypical features, low IQ, early onset and a chronic course may be especially likely to demonstrate congenital brain anomalies. ${ }^{434}$ Obvious structural anomalies which are occasionally identified by neuroimaging studies of psychiatric hospital cohorts, though of interest in their own right, may be of value in providing clues as to the location of more prevalent lesions of a subtler kind. They may also give hints as to aetiology. It should be noted that intrauterine influenza infection and maternal alcohol consumption may cause agenesis of the $\mathrm{CC},{ }^{910}$ and both have been proposed as aetiological factors in schizophrenia. ${ }^{45} 46$ The many genetic anomalies found in familial and sporadic cases of callosal agenesis may point to candidate regions for genetic markers in psychotic illnesses. It is conceivable though highly speculative, that if the genetic control of the development of callosal fibres was disrupted in a subtle way, short of agenesis, psychosis may ensue.

Disorders of interhemispheric integration can be considered as a plausible model for a range of psychiatric phenomena from "alexithymia" to delusions and hallucinations. ${ }^{47-51}$ Support comes from some neuropathological ${ }^{52}$ and MRI studies of the CC in psychiatric patients ${ }^{53}$ which found differences in comparison with normal controls. Another line of evidence linking psychiatric symptoms and the $\mathrm{CC}$, is the high incidence of such symptoms, ${ }^{54}$ in patients with tumours of that region. Others have reported series with psychotic and affective symptoms. ${ }^{556}$ This evidence provides some of the rationale for pursuing dysfunctional interhemispheric communication in cases of psychosis. ${ }^{5758}$

Clearly, the CC itself need not be involved directly in the causation of psychosis. As well as allowing communication between the hemispheres, the CC may be necessary to regulate the activity within them ${ }^{30}$ and it may be the lack of this which predisposes to psychosis. ${ }^{49-59}$ Indeed the inhibitory nature of the $\mathrm{CC}^{60}$ is suggested by the high incidence of seizures in agenesis. Similarly, altemative pathways for interhemispheric communication, which develop in the absence of a functioning CC, may be especially susceptible to misconnection, a proposed mechanism for producing psychotic symptoms. ${ }^{6162}$ Finally, the associated cerebral anomalies such as those involving limbic structures, which occur in tandem with callosal agenesis, could be of specific aetiological importance for psychiatric illnesses. In any event, further studies of psychiatric disorders in patients with callosal anomalies should increase our understanding of the cerebral basis of many psychiatric conditions.

We thank Drs J Bird, P Taylor, P Fenwick and E Taylor for their permission to report on their patients, and Dr Laura Goldstein who carried out some of the neuropsychological assessments.

1 Rakic P, Yakovlev PI. Development of the corpus callosum and cavum septi in man. $\mathcal{F}$ Comp Neurol 1986;132: 45-72.

2 Loeser JD, Alvord EC. Agenesis of the corpus callosum. Brain 1968;91:553-70.

3 Aicardi J, Chevrie JJ, Baraton J. Agenesis of the corpus callosum. In: Myriantholopolus NC, ed. Handbook of clinical neurology vol 6: malformations. Amsterdam: Elsevier, North Holland Biomedical Press, 1987;149-73.

4 Ramaekers G. Embryology and anatomy of the corpus callosum. In: Njiokiktjien C, Ramaekers G, eds. Paediatric behavioural neurology, vol 3. The Child's Corpus Callosum. Amsterdam: Suyi Publications, 1991:24-39.

5 S McLeod NA, Williams JP, Machen B, Lum GB. Normal and abnormal morphology of the corpus callosum. Neurology 1987;37:1240-2.

6 Serur D, Jeret J S, Wisniewski K Agenesis of the corpus callosum: clinical, neuroradiological and cytogenetic studies. Neuropediatrics 1988;19:87-91.

7 Njiokiktjien C. Absence of the corpus callosum: Clinicopathological correlations. In: Niiokiktjien C, Ramaekers G, eds. Paediatric behavioural neurology, vol 3. The child's corpus callosum. Amsterdam: Suyi Publications, 1991:235-50.

8 Kolodny EH. Agenesis of the corpus callosum: a marker of inherited metabolic disease? Neurology 1989;39:847-8.

9 Jones K, Smith DW. Recognition of the fetal alcohol syndrome in early infancy. Lancet 1973;ii:999-1001.

10 Conover PT, Roessmann U. Malformation complex in an infant with intrauterine influenza viral infection. Arch Pathol Lab Med 1990;114:535-8.

11 Domingnez R, Vila-Coro AA, Slopis JM, Bohan TP. Brain and other abnormalities in infants with an in utero exposure to cocaine and other street drugs. $A m \mathcal{F}$ Dis Child 1991;145:688-95.

12 Byrd SE, Radkowski A, Flannery A, McLone DG. The clinical and radiological evaluation of absence of the corpus callosum. Eur $\mathcal{f}$ Radiol 1990:10;65-73.

13 Gazzaniga M. The bisected brain. New York: AppletonCentury-Crofts, 1970.

14 Sperry RW. Consciousness, personal identity and the divided brain. Neuropsychologia 1984;17:153-66.

15 Benson DF, Zaidel E. The dual brain. New York: Guilford Press, 1985.

16 Zaidel E, Clarke JM, Suyenobu B. Hemispheric independence: a paradigm case for cognitive neuroscience. In: Scheibel A, Weschler A, eds. Neurobiology of higher cognitive functioning. New York: Guilford Press, 1990.

17 Chiarello C. A house divided? Cognitive functioning with callosal agenesis. Brain Lang 1980;11:128-58.

18 Milner AD. Neuropsychological studies of callosal agenesis. Psychol Med 1983;13:721-5.

9 Lehmann HJ, Lampe H. Observations on the interhemispheric transmission of information in 9 patients with corpus callosum defect. Eur Neurol 1970;4:129-47.

20 Ettlinger G, Blakemore CB, Milner AD, Wilson J. Agenesis of the corpus callosum: a further behavioural investigation. Brain 1974;97:225-34

21 David AS. Stroop effects within and between the cerebral hemispheres: studies in normals and acallosals. Neuropsychologia 1992;30:161-75.

22 Lassonde M, Sauerwein H, McCabe N, Laurencelle L Geoffroy $G$. Extent and limits of cerebral adjustment to Geoffroy G. Extent and limits of cerebral adjustment to early section or congenital absence of the
sum. Behav Brain Res 1988;30:165-81.

23 Carpenter MB, Druckmiller WH. Agenesis of the corpus callosum diagnosed during life. Arch Neurol Psychiat 1953;69:305-22.

24 Thieffry S, Lefebvre J, Lepoutre J, Faure C, Masselin S. Contribution a l'étude radiologique des malformations du plan sagittal interhémisphèrique. Acta Radiol 1958 50:242-52.

25 Gross H, Hoff $H$. Sur les malformations ventriculaires dépendante des dysgénésies commissurales. In: Heuye G, Feld M, Gruner J, eds. Malformations Congenitales du Cerveau. Paris: Masson, 1959:329-51.

26 Grogono JL. Children with agenesis of the corpus callosum Dev Med Child Neurol 1968;10:613-16.

27 Courville CB. Congenital malformations and abnormalities of the central nervous system. Pathology of the central 
nervous system, 3rd ed. Califomia: Pacific Press, 1950 63-94.

28 Myrianthopoulos NC. Epidemiology of CNS Malformations, In: Vinken PJ, Bruyn G, Klawans HL, eds. Malformations. Handbook of neurology, rev series 6. Amsterdam: Elsevier Science Publishers, 1987:49-70.

29 Swayze VW, Andreasen NC, Ehrhardt JC, Yoh WTC, Alliger RJ, Cohen GA. Developmental abnormalities of the corpus callosum in schizophrenia. Arch Neurol 1990;47: 805-8.

30 Jeeves MA. Agenesis of the corpus callosum. In: Boller F, Grafman J, eds. Handbook of neuropsychology, vol 4. Grafman J, eds. Handbook of neuropsycholog

31 Slager UT, Kelly AB, Wagner JA. Congental absence of the corpus callosum: report of a case and review of the literature. N Engl $\mathcal{Y}$ Med 1957:256:1171-6

32 MacPherson RI, Holgate RC, Londeman SK Midline central nervous lipomas in children. F Can Assoc Radio 1987;38:264-70.

33 Lewis SW, Reveley MA, David AS, Ron MA. Agenesis of the corpus callosum and schizophrenia: a case report. Psychol Med 1988;18:341-7.

34 Velek M, White LE, Williams JP, Stafford RL, Marco LA. Psychosis in a case of corpus callosum agenesis. Ala Med 1988;58:27-9.

35 Rutter M, Graham P, Yule, W. A neuropsychiatric study in Childhood. Clinics in Developmental Medicine nos 35/36. London: Heinemann Medical, 1970.

36 Wing L. Asperger's Syndrome: a clinical account. Psychol Med 1981;11:115-29.

37 Wolff S. "Schizoid" personality in childhood and adult life I-III. Brit f Psychiat 1991;159:615-35.

38 Voeller KKS. Right hemisphere deficit syndrome in children. Am F Psychiat 1986;143:1004-9.

39 Davison K, Bagley CR. Schizophrenia-like psychoses associated with organic disorders of the central nervous system. In: Herrington $\mathrm{RN}$, ed. Current problems in neuropsychiatry, Brit Psychiat Special Publ 4. Ashford, Kent: Headley 1969

40 Owens DGC, Johnstone EC, Bydder GM, et al. Unsuspected organic disease in chronic schizophrenia demonstrated by computerised tomography. $\mathcal{f}$ Neurol Neurosurg Psychiatry 1980;43:1065-9.

41 Lewis SW. Computerised tomography in schizophrenia 15 years on. Brit $\mathcal{F}$ Psychiat 1990;157 (suppl9):16-24.

42 Jones P, Murray RM. The genetics of schizophrenia is the genetics of neurodevelopment. Brit $\mathcal{F}$ Psychiat 1991;158: 615-23.

43 Reveley AM, Reveley MA. Aqueduct stenosis and schizophrenia. F Neurol Neurosurg Psychiatry 1983;46:18-22.

44 Lewis SW, Mezey GC. Clinical correlates of septum pellucidum cavities: an unusual association with psycho- sis. Psychol Med 1985;15:43-54.

45 O'Callaghan E, Sham P, Takei N, Glover G, Murray RM Schizophrenia after prenatal exposure to $1957 \mathrm{~A} 2$ influenza epidemic. Lancet 1991;337:1248-50.

$46 \mathrm{Lohr}$ JB, Bracha S. Can schizophrenia be related to prenatal exposure to alcohol? Some speculations. Schiz Bull 1989;4:595-603.

47 Beaumont JG. Dimond SJ. Brain disconnection and schizophrenia. Brit $\mathcal{F}$ Psychiat 1973;123:661-2.

48 Galin D. Implications for psychiatry of left and right cerebral specialization. Arch Gen Psychiat 1974;31: cerebral

49 Cutting J. The psychology of schizophrenia. Edinburgh: Churchill Livingstone, 1985 .

50 David AS. Tachistoscopic tests of colour naming and matching in schizophrenia: evidence for posterior callosum dysfunction? Psychol Med 1987;17:621-30.

51 David AS. Reading about the split brain syndrome. Brit $\mathcal{f}$ Psychiat 1989;154:422-5.

52 Rosenthal R, Bigelow LB. Quantitative brain measures in chronic schizophrenia. Brit $\mathcal{f}$ Psychiat 1972;121:259-64

53 Raine A, Harrison GN, Reynolds GP, Sheard C, Cooper JE Medley I. Structural and functional characteristics of the corpus callosum in schizophrenics, psychiatric controls, and normal controls. Arch Gen Psychiat 1990;47: $1060-4$.

54 Ironside $R$, Guttmacher $M$. The corpus callosum and its tumours. Brain 1929;52:442-84.

55 Nasrallah HA, McChesney CM. Psychopathology of corpus callosum tumours. Biol Psychiat 1981;16:663-9.

56 Tanaghow A, Lewis J, Jones GM. Anterior tumour the corpus callosum with atypical depression. Brit $\mathcal{F}$ Psychiat 89;155:854-6.

57 Coger RW, Serafetinides EA. Schizophrenia, corpus callosum, and interhemispheric communication: a review. Psychiat Res 1990;34:163-84

58 Doty RW. Schizophrenia: a disease of interhemispheric processes at forebrain and brainstem levels? Behav Brain Res 1989;34:1-33.

59 Green P, Hallet S, Hunter M. Abnormal interhemispheric integration and hemisphere specialization in schizophrenics and high-risk children. In: Gruzelier JH, FlorHenry P, eds. Laterality and psychopathology. Amsterdam: Elsevier, 1986:443-70.

60 Cook ND. The brain code: mechanisms of information transfer and the role of the corpus callosum. London: Methuen, 1986.

61 Nasrallah HA. The unintegrated right cerebral hemispheric consciousness as alien intruder. Comp Psychiat 1985;26: 273-82.

62 Randall PL. Schizophrenia, abnormal connection and brain evolution. Med Hypotheses 1983;10:247-80 